
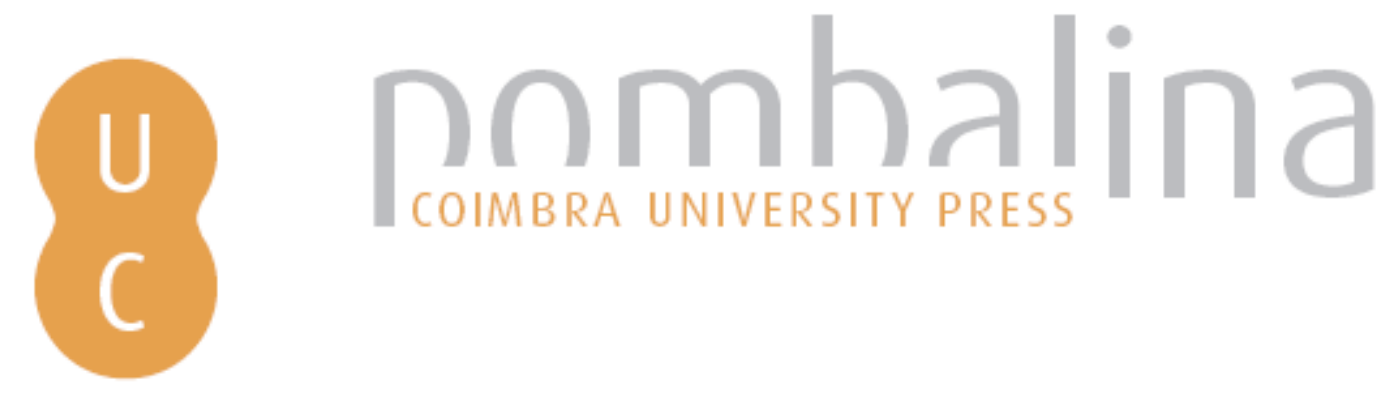

\title{
Do biológico ao social, em tempos de adversidade
}
Autor(es):
Quartilho, Manuel João
Publicado por: Imprensa da Universidade de Coimbra
URL
persistente:
URI:http://hdl.handle.net/10316.2/36630
DOI:
DOI:http://dx.doi.org/10.14195/978-989-26-0968-3_1

Accessed : $\quad$ 26-Apr-2023 14:11:36

A navegação consulta e descarregamento dos títulos inseridos nas Bibliotecas Digitais UC Digitalis, UC Pombalina e UC Impactum, pressupõem a aceitação plena e sem reservas dos Termos e Condições de Uso destas Bibliotecas Digitais, disponíveis em https://digitalis.uc.pt/pt-pt/termos.

Conforme exposto nos referidos Termos e Condições de Uso, o descarregamento de títulos de acesso restrito requer uma licença válida de autorização devendo o utilizador aceder ao(s) documento(s) a partir de um endereço de IP da instituição detentora da supramencionada licença.

Ao utilizador é apenas permitido o descarregamento para uso pessoal, pelo que o emprego do(s) título(s) descarregado(s) para outro fim, designadamente comercial, carece de autorização do respetivo autor ou editor da obra.

Na medida em que todas as obras da UC Digitalis se encontram protegidas pelo Código do Direito de Autor e Direitos Conexos e demais legislação aplicável, toda a cópia, parcial ou total, deste documento, nos casos em que é legalmente admitida, deverá conter ou fazer-se acompanhar por este aviso.

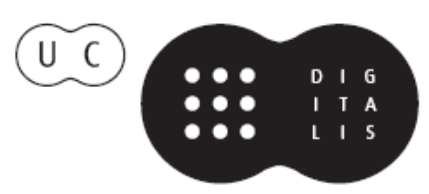




\section{CADERNOS DE PSIOUIATRIA SOCIAL E CULTURAL}

\section{\# 0}

MANUEL JOÃO QUARTILHO (COORD.)

HELDER ALMEIDA

ISABEL FAZENDA

ISABEL GIL

LINDA FERNANDES

MARIA DE FÁTIMA SOUSA

NUNO CARRILHO

RITA ALCAIRE

IMPRENSA DA UNIVERSIDADE DE COIMBRA COIMBRA UNIVERSITY PRESS 


\section{Do biológico ao social, em tempos de adversidade}




\section{Manuel João Rodrigues Quartilho3}

Professor Auxiliar da Faculdade de Medicina de Coimbra

\section{Resumo}

Este capítulo considera a epigenética como elo potencial de ligação entre os genes e o ambiente, entre as ciências naturais e sociais. Interpreta o desenvolvimento à custa de uma perspetiva dialética. Critica as orientações epidemiológicas baseadas na biomedicina e nos estilos de vida. Valoriza o conceito de determinantes sociais e a sua relação com as causas fundamentais, justiça social e direitos humanos. Desenvolve ainda aspetos relacionados com as desigualdades e a pobreza em ambientes de austeridade, provocados pela recessão económica, em Portugal. São ainda feitas considerações sobre as medidas de progresso social nos diferentes países.

Palavras chave: Epigenética, interações gene/ambiente, desenvolvimento, perspetiva dialética, biomedicina e estilos de vida, direitos humanos, causas fundamentais, determinantes sociais, desigualdades, desemprego, pobreza, recessão.

\section{Abstract}

This chapter looks at epigenetics as a potential theoretical bridge between genes and environment, between the natural sciences and the social sciences. It looks at development through the lens of a dialectic perspective, criticizing epidemiologic orientations based on biomedical and lifestyle principles. The text takes preference for the concept of social determinants of health and its relationship with fundamental causes, human rights and social justice. Looking at the health effects of economic recessions, the chapter concludes with some considerations related to health inequalities, poverty and wellbeing politics in Portugal and abroad.

Keywords: Epigenetics, gene/environment interactions, development, dialectic perspective, biomedicine and lifestyles, human rights, fundamental causes, social determinants, health inequalities, unemployment, poverty, recession.

3 Professor auxiliar da Faculdade de Medicina de Coimbra. Assistente hospitalar graduado de psiquiatria do CHUC. Coordenador do Mestrado em Psiquiatria Social e Cultural. 


\section{Biológico}

As interpretações plausíveis não serão melhores que as explicações causais, em particular quando a descoberta de uma explicação causal nos obriga a artificializar o objeto do nosso estudo até um ponto dificilmente reconhecível como sendo representativo da vida humana? O estudo do espírito humano é tão difícil, tão constrangido pelo dilema de ser ao mesmo tempo o objeto e o agente do seu próprio estudo, que não pode limitar as suas investigações a formas de pensar oriundas da Física. Pelo contrário, a tarefa é tão atrativa e importante que merece toda a rica variedade de contributos que podem ser oferecidos para a compreensão do sentido que o homem confere ao seu mundo, aos seus semelhantes e a si próprio (Jerome Bruner, Acts of Meaning) ${ }^{4}$

A possibilidade de um diálogo construtivo entre diferentes conhecimentos disciplinares, mesmo que a propósito de um único tema científico, pode revestir-se de dificuldades quase irresolúveis. Um livro recente confirma estas dificuldades, em função dos diferentes focos e interesses com que olhamos para a realidade.

Mesmo quando estudam o mesmo assunto, tal como a memória, os psicólogos cognitivistas, os biólogos moleculares e os imagiologistas cerebrais têm poucos pontos de contacto e trabalham com diferentes entendimentos dos fenómenos... Dois livros de texto sobre a memória, por exemplo, cada um deles escrito por um especialista de topo na matéria, um biólogo molecular e um psicólogo cognitivista, não partilham praticamente nenhumas referências (Rose e Rose, 2012).

A memória é apenas um tema divergente, entre muitos. Steven Rose, biólogo, conta-nos a história de cinco colegas com diferentes versões para o comportamento de uma rã que saltou para dentro de água, junto a um lago, quando sentiu a presença próxima de uma serpente (Rose, 2005). A verdade é que todos os biólogos tinham razão. Não havia uma resposta verdadeira. As respostas mais úteis dependem do motivo pelo qual a pergunta é feita. E a história da rã faz justiça, afinal, à necessidade de um pluralismo epistemológico que dignifique as nossas capacidades de pensar e compreender (Rose, 2005).

Todo o argumento, portanto, deve ser situado. Dentro das ciências naturais, tal como nas ciências sociais, existem sempre múltiplas perspetivas e possibilidades de análise. A esquizofrenia, ou a depressão, podem suscitar tanto uma interpretação bioquímica como um olhar antropológico. As possibilidades de diálogo entre as ciências naturais e as ciências sociais apresentam, neste contexto, enormes dificuldades. A recolha de informações tende a ser um processo de filtragem, seletivo, muitas vezes confirmatório. Mas não obstante o cenário pessimista, as ciências naturais e as ciências sociais vislumbram hoje uma hipótese de "amizade crítica" baseada em conceitos que procuram explicar a "entrada da experiência para debaixo da pele" (McEwen, 2012). A noção de incrustação biológica (biological embedding), por

4 As traduções presentes neste capítulo são da responsabilidade do autor. 
exemplo, refere-se à possibilidade de as experiências biográficas poderem determinar alterações biológicas que causam, em última análise, a eclosão subsequente de patologias variadas. Na verdade, se dissermos que as experiências de adversidade precoce, na infância, se transformam em patologia na idade adulta porque a criança ficou psicologicamente traumatizada, esta não é uma explicação, é uma descrição linear, mecanicista, um disparate conceptual. Mas se quisermos estudar um substrato físico que explique melhor os processos de mediação entre adversidade precoce e patologia do adulto, então podemos aceitar que a reinterpretação da biologia humana no seu contexto social requer uma ponte conceptual entre as ciências naturais e sociais, à custa de um processo de incrustação biológica que ocorre, portanto, quando a experiência das pessoas gets under the skin e altera os processos biológicos humanos (Hertzman e Boyce, 2010).

Este processo depende, eventualmente, de complexos mecanismos de regulação epigenética que permitem a referida ponte entre a biologia e o ambiente. Em 2010, a Time Magazine anunciou que "o novo campo da epigenética mostra como o seu ambiente e escolhas podem influenciar o seu código genético - o seu e o dos seus filhos" (Time Magazine, 8 de janeiro de 2010). A epigenética, explicava o artigo, "é o estudo de alterações na atividade dos genes que não envolvem alterações no código genético mas que, ainda assim, são transmitidas a pelo menos uma geração". Estas formas de expressão genética seriam centralizadas no epigenoma ${ }^{5}$, que por sua vez seria responsável pela ativação ou desativação dos genes, sob a influência de fatores ambientais diversos, externos ou internos ao organismo, desde uma modificação na concentração da glicose a um impulso elétrico, ou a uma interação social (Meaney, 2010:50). Compreender as consequências epigenéticas das exposições sociais, neste sentido, pode contribuir para revolucionar a medicina, as ciências sociais e as humanidades. Ou seja, a epigenética surge como uma ponte entre as ciências sociais e biológicas, prometendo uma compreensão realmente integrada da saúde e comportamento humanos (McGowan e Szyf, 2010).

A epigenética tem antecedentes ligados a um período histórico sombrio, um período de fome conhecido por Dutch Hunger Winter, entre finais de 1944 e princípios de 1945, no culminar da Segunda Grande Guerra (Carey, 2012). A parte ocidental da Holanda, ainda sob o jugo alemão, foi então vítima de uma dramática redução na distribuição de alimentos. Morreram mais de 25.000 pessoas até Maio de 1945, altura em que foi interrompido o bloqueio. Esta situação permitiu uma investigação

5 Os 23.000 genes que as crianças herdam dos pais podem ser considerados como o "genoma estrutural", uma espécie de hardware que precisa de um sistema operativo que o informe sobre o que deve fazer. O epigenoma é este sistema operativo, um sistema que determina quais as funções que o hardware (genoma) deve, ou não, realizar (National Scientific Council on the Developing Child, 2010).

6 No passado, os cientistas sociais tendiam a ignorar as explicações genéticas, porque a sua aceitação implicava uma espécie de rendição à supremacia explicativa do gene, perante a irrelevância ou superficialidade do "social". Mas a epigenética pode ajudar os sociólogos a especificar e medir alguns dos múltiplos mecanismos associados às "causa fundamentais" (ver adiante), sem terem que privilegiar o biológico ou o social e, em particular, sem terem que reconhecer a supremacia explicativa do gene. A epigenética relaciona-se com mecanismos de expressão genética, não com a sequência genética. Não tem a ver com o modo através do qual a variação genética produz variação no organismo. Pelo contrário, diz respeito aos modos de aparecimento da variação, apesar de uma genética basicamente similar (Landecker e Panofsky, 2013). 
epidemiológica sobre os efeitos da fome no peso das crianças, ao nascimento. Se uma mãe tivesse tido uma alimentação normal na altura da concepção e uma alimentação deficiente nos últimos meses da gravidez, as crianças apresentavam um baixo peso ao nascimento. Se, pelo contrário, a mãe tivesse tido uma alimentação deficiente apenas nos primeiros três meses de gravidez, com normalização subsequente, então a criança era mais suscetível de nascer com um peso normal.

E o que aconteceu, entretanto, às crianças? As crianças de baixo peso continuaram com baixo peso durante as suas vidas, com taxas de obesidade inferiores às da população geral. E as crianças cujas mães tinham tido uma alimentação deficiente apenas no início da gravidez, por seu lado, evidenciaram taxas de obesidade superiores ao normal. Mais interessante, os netos das mulheres que tiveram uma alimentação deficiente nos primeiros meses de gravidez apresentaram alguns dos mesmos efeitos. Ou seja, aquilo que aconteceu numa população de mulheres grávidas ter-se-á transmitido aos filhos dos filhos 7 . Ora, porque é que algo que acontece cedo, no processo de desenvolvimento, eventualmente ainda no decurso da vida intrauterina, tem consequências bastante mais tarde, na saúde física e mental do adulto? Talvez a epigenética seja a resposta biológica à questão formulada. E talvez responda, igualmente, a uma assinalada prevalência de $50 \%$ para a esquizofrenia em pares de gémeos monozigóticos. Diferenças ao nível da experiência e/ou do ambiente podem determinar discordância na natureza das marcas epigenéticas em zonas específicas do genoma, causando diferenças fenotípicas apesar de um genótipo comum (Zhang e Meaney, 2010). Afinal, quando dois indivíduos geneticamente idênticos são diferentes nalguma das suas características mensuráveis, ou quando uma ocorrência ambiental tem consequências biológicas muito para além do acontecimento inicial, quando o código genético não explica tudo, "isto é a epigenética em ação", através de mecanismos moleculares que não alteram os genes, mas sim os seus modos de expressão (Carey, 2012). Numa perspetiva otimista, a epigenética pode ser considerada como o elo que faltava nas relações entre nature e nurture, um instrumento que nos ajuda a compreender os efeitos do ambiente, frequentemente irreversíveis, sobre a vida das pessoas. Numa leitura mais sombria, compulsando muito da vasta literatura sobre o tema, a epigenética ameaça assumir-se como um novo determinismo somático, com capacidade potencial para alimentar novas formas de reducionismo (Lock, 2013).

De qualquer modo, a compreensão da natureza das respostas epigenéticas às exposições ambientais está ainda a dar os seus primeiros passos. Existem dúvidas, e até mesmo alguma frustração, quanto à legitimidade da extrapolação de resultados obtidos em estudos animais (Miller, 2010). Talvez

7 Esta possibilidade de uma transmissão não genética transporta-nos até um cientista do século XVIII, chamado Lamarck, cujas teorias propuseram uma forma de transmissão de características adquiridas, ou "soft inheritance". O seu exemplo mais citado, o exemplo das girafas, defendeu que estas alongaram o pescoço, ao longo do processo evolutivo, devido à necessidade de se alimentarem a partir de árvores altas. O alongamento progressivo do pescoço das girafas, segundo Lamarck, libertava fluidos que permitiam, às gerações seguintes, ter pescoços cada vez mais compridos. Criticado e ridicularizado, as suas teses foram ofuscadas pelos contributos de Darwin (Spector, 2013). Mas hoje olhamos para Lamarck como um dos precursores da epigenética. Se pensarmos no âmbito da prática clínica psiquiátrica, a transmissão de características adquiridas significa, por exemplo, que os filhos de pais deprimidos herdam não apenas os genes que lhes aumentam o risco de depressão, mas também o pai deprimido (Meaney, 2001). 
seja possível compreender melhor, no futuro, as complexas relações entre genética, epigenética e contextos sociais, ou seja, as bases biológicas do risco e da resiliência (Champagne, 2010). Mas na investigação epigenética para a próxima década, como referiu Nessa Carey,

Haverá esperança e extravagância, promessas exageradas, caminhos sem saída, movimentos errados e ocasionalmente mesmo alguma investigação desacreditada. A ciência é um esforço humano e por vezes corre mal. Mas no final dos próximos 10 anos compreenderemos melhor as respostas para algumas das mais importantes questões da biologia. Neste momento não podemos prever quais poderão ser essas respostas e nalguns casos não temos sequer uma certeza em relação às perguntas. Mas uma coisa é certa. A revolução epigenética está em marcha (Carey, 2012:312).

Os genes, entretanto, perderam o seu estatuto privilegiado. A genómica não cumpriu as suas promessas, não anulou o enorme fosso entre a investigação básica e as aplicações clínicas, não confirmou as previsões segundo as quais "o nosso destino está nos nossos genes" (Gruber, 2013). A "astrologia genética está em dificuldades" (Jablonka, 2013: 80). O Projeto do Genoma Humano custou 3 biliões de dólares e, décadas depois, defraudou as expectativas (Ho, 2013). É verdade que os cientistas e o público em geral não podem desvalorizar, embora também não devam exagerar, os méritos da investigação genética (Cranor, 2013). Mas o gene deixou de ser o maestro, o condutor da orquestra. A música não está predeterminada. E do mesmo modo que se pode mudar a música, também podemos alterar os nossos genes, mudar os destinos dos nossos filhos e dos nossos netos (Spector, 2013: 293). Já não existem "genes para...", porque o conceito preformacionista da ação genética é inadequado (Kendler, 2005). O genoma não é um modelo Lego e os genes não fazem parte de uma qualquer estrutura estática a aguardar auto-ativação. O genoma deve ser considerado como um ecossistema, mais fluido, mais dinâmico e mais interativo (Krimsky, 2013). Deste modo, compreende-se que os mecanismos epigenéticos apareçam como interface entre o genoma e os seus ambientes, regulando a expressão genética. De acordo com Richard Lewontin, um maior progresso na nossa compreensão da natureza requer que reconsideremos a iniludível relação entre o exterior e o interior, entre o organismo e o ambiente (Lewontin, 2001:47). Uma visão alternativa dos organismos vivos, uma visão que reconhece a importância dos genes sem aceitar o determinismo genético, é uma perspetiva que procura compreender as pessoas e as suas trajetórias, no espaço e no tempo. Neste esquema teórico, portanto, a nossa atenção deve deslocar-se dos genes para o organismo em desenvolvimento (Rose e Rose, 2012).

Esta é uma posição congruente com as teses de Stephen Jay Gould (1941-2002), a propósito da polémica sociobiológica, visando compreender as propriedades emergentes e irredutíveis que resultam da interpenetração entre genes e ambiente (Gould, 1988: 225). Diálogo, portanto, entre biologia e ambiente, sem concessões à rigidez determinista. Richard Levins e Richard Lewontin (1985) desenvolveram as premissas teóricas de um programa dialético em biologia, assumindo o seu comprometimento ideológico com a tradição marxista. Proclamaram a mudança como característica central 
dos sistemas, resultante de relações internas e externas. Este fenómeno de mudança resultaria da heterogeneidade interna dos sistemas, eventualmente produtora de uma instabilidade dinâmica que originaria desenvolvimento interno à custa de partes oponentes, e de uma relação com o mundo externo que influenciaria e seria influenciado pelo citado desenvolvimento. A afirmação de que todos os sistemas são internamente heterogéneos levou os autores a concluir pela não existência de "unidades básicas" na origem dos processos causais, assim legitimando a investigação de cada nível organizativo e dispensando a necessidade de localização e identificação das referidas unidades. O método dialético enfatiza pois a interconexão universal, a heterogeneidade interna de todos os sistemas, a interpenetração de opostos e a existência de níveis integrativos simultaneamente autónomos e em interação recíproca (Quartilho, 1988).

Mais recentemente, Steven Rose (2005) defendeu a necessidade de uma biologia integradora, holista, aberta à complexidade e à diversidade epistemológica nos nossos esforços de compreensão da natureza e significado da vida. Coerente com uma perspetiva dialética, o autor defende que é falaciosa "a implicação de que o mundo está dividido em domínios de causalidade incomensuráveis, em que as explicações são sociais ou biológicas, com as suas sedutoras dicotomias nature or nurture, genes ou ambiente". Os fenómenos da vida, acrescenta Rose, "são sempre simultaneamente sobre nature e nurture, e os fenómenos da existência e experiência humanas são sempre simultaneamente biológicos e sociais" (Rose, 2005: 279). Numa palavra, somos o produto de uma dialética constante entre o "biológico" e o "social" (Rose, 2005: 6).

Esta perspetiva dialética sobre a nature e a nurture é uma perspetiva segundo a qual, afinal, ambas se constituem a si próprias; é uma orientação que defende, mais uma vez, "uma unidade de opostos mediante a qual o desenvolvimento não ocorre sem ambos, e ainda uma interpenetração de opostos na medida em que a nature modifica a nurture e inversamente a nurture modifica a nature... Mais importante, sem uma, a outra não existiria" (Sameroff, 2010). O debate nature-nurture é aliás "uma coisa que já foi resolvida vezes sem conta e que, afinal, continua por resolver" Dale Goldhaber (2012), a questão é como a daquelas velas que usávamos nos bolos de aniversário quando éramos crianças, aquelas que acendiam, que se apagavam quando soprávamos e que voltavam a acender-se de seguida, até voltarmos a soprar, para se acenderem de novo. O velho debate clássico é um exercício reducionista que questiona as contribuições relativas e independentes da genética e do

8 Do ponto de vista histórico, pelo menos no âmbito da psicologia do desenvolvimento, o pêndulo tem oscilado sucessivamente entre nature e nurture, entre as características intrínsecas da criança e as propriedades extrínsecas do ambiente. Francis Galton, no século XIX, favoreceu o papel central da nature. Os anos 20 assistiram a uma influência crescente da nurture, à custa da teoria da aprendizagem, um paradigma que alimentou inúmeros trabalhos de investigação até aos anos 1950. Nos anos 1960, a nature voltou a ganhar proeminência, à custa dos desenvolvimentos conceptuais em etologia, genética comportamental e teoria cognitiva. Nos anos 80, as questões relacionadas com a pobreza e os conceitos de ecologia social e desconstrução cultural, por sua vez, empurraram novamente o pêndulo para o lado da nurture. Entretanto, com a viragem do século, a biologia molecular e as neurociências devolveram à nature, mais uma vez, uma renovada importância conceptual na investigação do comportamento humano. Talvez um novo ciclo da nurture, finalmente, possa ser hoje anunciado pela chamada revolução epigenética (Sameroff, 2010). 
ambiente para o desenvolvimento individual. De algum modo, é um debate ultrapassado, obsoleto, sem resolução possível. O novo debate, holista e sistémico, admite partes contendoras que reconhecem o caráter essencial e inseparável da nature e da nurture. A psicologia evolutiva e a perspetiva sistémica participam neste novo debate e aceitam, ambas as orientações, uma interdependência sinérgica entre nature e nurture. A psicologia evolutiva centra a sua atenção nos antecedentes mais distais do nosso desenvolvimento, privilegiando mecanismos de seleção natural e adaptação modular ${ }^{9}$. A perspetiva sistémica, por sua vez, encerra uma orientação holista, argumentando não poder haver uma distinção entre nature e nurture porque o processo de desenvolvimento requer uma relação de interdependência entre ambas. Inspirada nos trabalhos de Gilbert Gottlieb (1929-2006), esta orientação defende que não existe uma correspondência linear entre genótipo e fenótipo. Qualquer genótipo pode dar origem a uma ampla variedade de fenótipos. O desenvolvimento é interpretado com uma lente probabilística, como um processo bidirecional, dinâmico, implicando interdependências e níveis múltiplos. Para Michael Meaney, um dos principais mentores desta perspetiva, os esforços para diferenciar a nature da nurture traduzem mesmo uma "falácia biológica". Não há distinção possível porque não existe uma sem a outra, do mesmo modo que não existe largura sem comprimento, ou comprimento sem largura, quando queremos calcular a área do retângulo. Existe, ao invés, um "consenso interacionista" (Landecker e Panofsky, 2013), na medida em que os elementos de um sistema existem apenas na relação com outros elementos desse sistema. E qualquer tentativa de estudar um elemento independentemente dos outros é impossível porque esse elemento existe apenas na relação com todos os outros.

A perspetiva dialética é uma perspetiva dinâmica. Nesta medida, legitima um olhar crítico sobre o projeto neurobiológico em psiquiatria, um projeto reducionista tripartido, metodológico, ontológico e epistemológico (Kirmayer e Gold, 2012). Reducionista metodológico por assumir que é necessária, e suficiente, uma estratégia de redução de fenómenos complexos a componentes mais simples, com recurso a modelos animais e a projeções causais lineares, unidirecionais, ignorando mecanismos de causalidade recíproca. Reducionista ontológico por defender que os fenómenos de nível superior são constituídos pelos fenómenos de nível inferior, ou seja, que a mente não é mais do que o cérebro, sem outros mecanismos, de natureza psicológica ou social, a justificar os fenómenos mentais. Reducionista epistemológico, finalmente, por sustentar que é desnecessário o estudo dos fenómenos de ordem superior para a compreensão da experiência e comportamento humanos. Mais importante do que a queixa do doente, neste sentido, seria o implacável recurso ao "cerebroscópio" para nos certificarmos de que o doente, em boa verdade, está a sentir a dor que o traz à consulta médica.

O projeto neurobiológico em psiquiatria "encontra os seus limites num facto simples e muitas vezes repetido: as perturbações mentais são problemas das pessoas, não dos cérebros. As perturbações

9 Para a psicologia evolutiva, a mente é uma máquina cognitiva, um instrumento de processamento da informação composto por uma série de módulos específicos, por exemplo para a linguagem ou para o reconhecimento das faces, entre muitos outros, como se fosse um "canivete suíço". Jerry Fodor e Steven Pinker são dois importantes mentores da modularidade da mente (Rose, 2005: 101). 
mentais não são problemas de cérebros em laboratórios, mas sim de seres humanos no tempo, espaço, cultura e história" (Rose e Abi-Rached, 2013: 140). Do mesmo modo, as neurociências não consideram, e muito menos respondem, à questão fundamental das relações entre matéria e mente, corpo e mente, ou cérebro e mente. Quando parecem consegui-lo, tal resulta apenas de uma confusão, ou mesmo de uma convergência, de três relações muito diferentes entre si: correlação, causalidade e identidade. Com efeito, podem existir correlações entre a experiência de vermos a cara da pessoa que amamos e alguma atividade nalguma parte do sistema nervoso. Significa isto que o que vemos no exame imagiológico é a causa da experiência ou algo idêntico à experiência? Não, porque correlação não é causa e, muito menos, identidade (Tallis, 2011:85). A tecnologia imagiológica produz imagens visuais apelativas sobre processos invisíveis, legitimando a realidade das perturbações mentais ao abrigo do "ver para crer" (Kirmayer, 2012). Mas os "factos cerebrais" não são dados objetivos, inquestionáveis, antes emergem de comunidades de cientistas que trabalham coletivamente, com um "estilo de pensamento" particular, num tempo e período históricos determinados (Choudury et al., 2009). As explicações biológicas tendem a isentar as pessoas das complexidades sociais e culturais que infiltram os seus mundos. A redução da psiquiatria à neurobiologia, neste sentido, esconde drasticamente a importância da fenomenologia, das trajetórias biográficas e dos significados múltiplos, pessoais e morais, que integram o sofrimento das pessoas e povoam a prática clínica. Existem várias razões que parecem legitimar, hoje em dia, o reducionismo biológico em psiquiatria. De acordo com Laurence Kirmayer,

... as explicações biológicas trazem o anel da ciência dura; situam os problemas na interioridade do indivíduo e alinham, assim, com a ideologia cultural do individualismo; diferem a atenção das circunstâncias sociais e desigualdades para as quais algumas instituições deveriam assumir responsabilidade; prometem um arranjo tecnológico para o sofrimento causado pela incapacidade e pela doença. As explicações neurais evitam o pessoal e o particular em favor de uma abordagem associal, atemporal, impessoal, das ações e dos acontecimentos... (Kirmayer, 2012: 380)

\section{Social}

A saúde e as doenças têm uma inescapável dimensão social. Mas a teoria epidemiológica contemporânea vive ainda muito à custa dos conceitos da biomedicina e de estilo de vida (Krieger, 2011). Para a biomedicina, teorizar sobre a ocorrência de doenças é o mesmo que teorizar sobre as causas das doenças no interior dos organismos biológicos. Para o conceito de estilo de vida, a exposição a fatores de risco é, em larga medida, uma consequência que resulta de características e comportamentos individuais. Mas os modelos biomédicos do século Xx são tipicamente reducionistas, dado que privilegiam os mecanismos de doença e olham para os fatores sociais como se estes fossem secundários, ou mesmo irrelevantes. A doença nas populações é reduzida a uma questão de doença nos indivíduos, que por sua vez é reduzida a uma questão de disfunção biológica. Este substrato biológico, divorciado do seu contexto social, torna-se assim num local privilegiado para intervenções que têm, sobretudo, 
uma natureza médica. E ainda se deixam infiltrar, os modelos biomédicos, por uma ideologia de individualismo, cristalizada no estilo de vida, segundo a qual os indivíduos seriam livres de escolher os comportamentos relacionados com a saúde, como se fossem meros consumidores (Krieger, 2011).

Foi necessário encontrar uma alternativa a esta tradição biomédica, ou centrada no estilo de vida individual. Se é verdade que os estudos epidemiológicos tiveram (continuam a ter) um enorme sucesso na identificação dos fatores de risco proximais, também é verdade que foram (são) desvalorizadas, de algum modo, as condições sociais básicas na origem das doenças. A chamada transição epidemiológica, ocorrida nos anos 1960, primeiro no mundo industrializado e depois por toda a parte, contribuiu para mudanças significativas na teoria epidemiológica, dado que significou um regresso à whole person, à consideração conjunta das alterações biológicas e contextos sociais que geram e mantém o sofrimento causado pelas doenças. Chamou assim a atenção para as "causas das causas", para os fenómenos distais que justificam, a jusante, o aparecimento dos chamados fatores de risco proximais (Braveman, 2014). É verdade que os cuidados de saúde e os comportamentos individuais guardam uma estreita relação com a saúde e as doenças. Que as condições de vida e trabalho determinam o acesso aos cuidados de saúde e influenciam os comportamentos individuais. Mas as oportunidades e recursos sociais e económicos, finalmente, têm uma influência decisiva sobre as variáveis acima enunciadas. Estes últimos não são, necessariamente, os determinantes mais importantes ou decisivos, em todas as situações clínicas. Mas o seu estudo oferece possibilidades de compreensão e intervenção para além da orientação redutora, por vezes muito incompleta, oferecida pelo estudo descontextualizado dos fatores de risco proximal. Claro que as políticas económicas não são os agentes patogénicos per se. Mas são as "causas das causas" para o aparecimento de problemas de saúde - os fatores que determinam poderosamente quem vai ficar exposto aos maiores riscos, quem é mais vulnerável ao abuso de álcool, mais inclinado a contrair tuberculose num lugar para os sem abrigo, ou a cair nas malhas da depressão (Stuckler e Basu, 2013: 140). Esta causalidade social reveste-se de algumas características importantes, incluindo uma dimensão cognitiva e afetiva relacionada com significados e interpretações que afetam o autoconceito e a dignidade das pessoas, em contextos de perda, opressão, exclusão, discriminação, subordinação (Hertzman e Boyce, 2011). Os significados são essenciais para a compreensão do sofrimento alheio. Compreendemos melhor, e somos melhores na nossa humanidade, na medida em que formos capazes de pensar com o ponto de vista do outro, a partir do outro, na medida em que respeitarmos a dimensão ética e moral na relação com o outro. Face ao sofrimento de uma pessoa, de acordo com Kleinman e Benson (2006), "a primeira tarefa ética consiste no reconhecimento desse sofrimento. As questões morais precedem as questões epistemológicas e culturais. Existe algo mais básico e mais crucial do que a competência cultural para a compreensão da vida do doente, ou seja, o significado moral do sofrimento - o que é realmente importante para o doente, aquilo que o doente, no fundo, pode ganhar ou perder". Em suma, as pessoas não são números, nem são "descartáveis" 10.

\footnotetext{
10 Contra uma economia de exclusão, o Papa Francisco defendeu recentemente que "... Devemos dizer não a uma economia de exclusão e desigualdade social. Esta economia mata. Não é possível que a morte por enregelamento de um
} 
A epidemiologia social ofereceu várias alternativas teóricas à teoria epidemiológica convencional. Com diferentes designações, estas alternativas passaram a valorizar aspetos relacionados com saúde e direitos humanos, com as chamadas causas fundamentais ou, numa palavra, com os determinantes sociais da saúde. Nas relações entre saúde e direitos humanos, o tema da injustiça refere-se aos milhões de pessoas que morrem ou ficam incapacitadas e que de outro modo viveriam mais tempo ou teriam sido mais capazes - mais livres - para terem sido, ou terem feito, o que tivessem querido ser ou fazer se as suas condições sociais tivessem sido diferentes, se a capacidade de cada pessoa para ser saudável fosse reconhecida como um direito moral básico (Venkatapuram, 2011: 5). As causas fundamentais, por sua vez, têm efeitos sobre a saúde que não podem ser eliminados se considerarmos apenas os mecanismos que parecem associá-las às doenças. A característica essencial das causas fundamentais é que envolvem um acesso a recursos que podem ser usados para evitar riscos ou minimizar as consequências da doença, quando esta ocorre. Estes recursos incluem dinheiro, conhecimentos, poder, prestígio, e o tipo de vantagens interpessoais incorporadas nos conceitos de apoio social e redes sociais. Em suma, uma causa social fundamental envolve recursos que determinam o grau em que as pessoas são capazes de evitar riscos de morbilidade e mortalidade (Link e Phelan, 1995).

O que são os determinantes sociais da saúde? São as condições em que as pessoas nascem, crescem, vivem, trabalham e envelhecem, sendo que essas condições ou circunstâncias são influenciadas pela distribuição do dinheiro, poder e recursos a níveis global, nacional e local, e ainda responsáveis, muitas vezes, pelas iniquidades na saúde, pelas diferenças injustas e evitáveis no estado de saúde observado nos (e entre os) diferentes países (WHO, 2013). São estes os determinantes principais quanto à possibilidade de as pessoas adoecerem ou se manterem saudáveis, influenciando a medida em que a pessoa possui os recursos físicos, sociais e pessoais para conseguir concretizar aspirações, satisfazer necessidades e lidar com as suas circunstâncias de vida (Raphael, 2009: 2).

Os chamados "Factos Sólidos", enunciados por Wilkinson e Marmot (2003), assinalam alguns dos dados mais robustos em Epidemiologia Social. Por muito importante que seja a suscetibilidade individual, referem os autores, as causas comuns das doenças que afetam as populações são ambientais: vêm e vão mais depressa do que os lentos ritmos da mudança genética, dado que refletem as mudanças no modo como vivemos. É por isto que a esperança de vida aumentou de forma tão nítida nas últimas gerações; que alguns países europeus melhoraram o seu estado de saúde, em contraste com outros; e que as diferenças na saúde entre diferentes grupos sociais aumentaram ou diminuíram, na medida em que se

idoso sem-abrigo não seja notícia, enquanto o é a descida de dois pontos na bolsa. Isto é exclusão. Não se pode tolerar mais o facto de lançar comida no lixo, quando há pessoas que passam fome. Isto é desigualdade social. Hoje, tudo entra no jogo da competitividade e da lei do mais forte, onde o poderoso engole o mais fraco. Em consequência desta situação, grandes massas da população veem-se excluídas e marginalizadas: sem trabalho, sem perspetivas, num beco sem saída. O ser humano é considerado, em si mesmo, como um bem de consumo que se pode usar e depois deitar fora. Assim teve início a cultura do "descartável"... Já não se trata simplesmente do fenómeno de exploração e opressão, mas de uma realidade nova: com a exclusão, fere-se, na própria raiz, a pertença à sociedade onde se vive, pois quem vive nas favelas, na periferia ou sem poder já não está nela, mas fora. Os excluídos não são "explorados", mas resíduos, "sobras" (Evangelli Gaudium, 2013: 45). 
alteraram as respetivas condições sociais e económicas. Os factos sólidos incluem, nesta perspetiva, o gradiente social, o stress, os primeiros anos de vida, a pobreza e a desigualdade social, as condições de trabalho, o desemprego, o apoio social, o consumo e abuso de substâncias, a distribuição dos alimentos e o acesso a transportes. Consideremos, de forma resumida, apenas alguns destes "factos".

A pobreza, por exemplo, é geralmente responsável por uma prevalência aumentada de perturbações mentais que por sua vez perpetuam, através das consequências económicas na vida das pessoas, as situações de pobreza (World Health Report, 2001). Esta é também uma questão moral por estar associada não apenas ao desenvolvimento dos países mas também a questões mais amplas de saúde pública e direitos humanos, dado que todas as pessoas têm um direito inalienável à capacidade para serem saudáveis, compatível com uma dignidade humana igual para todos. A reivindicação moral é a de uma capacidade social para ser saudável e não diretamente a de certos "resultados na saúde", de um particular funcionamento biológico ou mental (Venkatapuram, 2011: 19). Em Portugal, a linha de pobreza corresponde a 421 Euros mensais (Farinha Rodrigues, 2013). A incidência de pobreza é de 18\% ${ }^{11}$. A pobreza infantil assume uma dimensão particularmente preocupante, com uma taxa de pobreza de 22,4\%. A taxa de pobreza dos idosos, por sua vez, diminuiu de cerca de 40\% em 1993 para 20\% em 2010. Infelizmente, não se verificou o mesmo com a pobreza infantil. Por tipo de família, verifica-se uma situação precária para muitas crianças. Com efeito, as famílias monoparentais e as famílias alargadas com crianças conjugam altas taxas de pobreza e de intensidade de pobreza, confirmando-se deste modo a preocupação que a pobreza infantil deve suscitar na sociedade portuguesa, dado que as crianças que crescem em agregados familiares de baixo estatuto socioeconómico são mais suscetíveis de viver em condições de habitação desfavoráveis e ser expostas a "dinâmicas familiares de risco", caracterizadas por relações interpessoais conflituais, por padrões de educação austera e agressiva e por outras formas de stress precoce que podem alterar as trajetórias de risco de doença na vida adulta (McEwen e Gianaros, 2010).

Os indicadores de pobreza face à condição perante o trabalho, por sua vez, mostram uma elevada incidência de pobreza entre as pessoas desempregadas (Farinha Rodrigues, 2013). E a inserção no mercado de trabalho não é suficiente para evitar as situações de pobreza, uma vez que cerca de $10,3 \%$ dos portugueses empregados são pobres. Mas a estreita relação entre pobreza e desemprego não deixa de ser óbvia. A taxa de pobreza, neste grupo de portugueses desempregados, é e 36\%, com uma intensidade que é também a maior, em todos os grupos considerados (empregados, reformados e outros inativos). E a proporção de pessoas desempregadas à procura de emprego conheceu uma subida entre 2012 e 2013 (INE, 2013).

11 Segundo os dados recolhidos pelo INE, a taxa de risco de pobreza aumentou para 18,7\% em 2012. Esta é a taxa mais elevada desde 2005, abrangendo cerca de 2 milhões de portugueses. Já em 2013, 25,5\% dos portugueses viviam em condições de privação material, e 10,9\% viviam mesmo em privação material severa. E a taxa de risco de pobreza para as famílias com crianças dependentes subiu para 22,2\%, contra os 20,5\% de 2011. A maior incidência revelou-se nas famílias mono-parentais com um filho a cargo $(33,6 \%)$ e nas famílias constituídas por dois adultos e três ou mais crianças (40,4\%) e por três ou mais adultos com menores (23,7\%). Para Carlos Farinha Rodrigues, os dados publicados são "a fotografia mais completa e consistente do impacto da austeridade na pobreza e na desigualdade" (Jornal Público, 25 de março de 2014 ). 
Ora, segundo um estudo recente, que examinou a relação entre a quantidade total de desemprego acumulado durante a Recessão Sueca de 1992-1996 12 e a mortalidade nos seis anos seguintes, os resultados apoiam uma interpretação causal para a associação entre desemprego e mortalidade. Os efeitos do desemprego na mortalidade por todas as causas, especialmente o desemprego de longo prazo, foram mais pronunciados nos homens, em comparação com as mulheres. Talvez este achado se explique pelo facto de os homens terem obtido um melhor estatuto social e mais prestígio à custa do emprego. O papel masculino do ganha-pão, real ou percebido, pode conferir ao desemprego um efeito potencialmente mais negativo, no caso dos homens (Garcy e Vagero, 2012). As medidas de prevenção do suicídio, neste contexto, devem incluir todas aquelas pessoas que passaram por uma situação de desemprego prolongado, durante a crise, especialmente no período em que as condições económicas começam a melhorar (Garcy e Vagero, 2013).

Um bom estado de saúde depende, em larga medida, de fatores que estão localizados fora dos cuidados de saúde. E uma sociedade que queira reduzir as desigualdades na saúde necessita de investir em várias frentes - investir na infância, na educação, na redução da desigualdade de rendimentos, na garantia de um trabalho saudável para todos, etc. (Shonkoff, Boyce \& McEwen, 2010). A saúde é demasiado importante para depender apenas dos cuidados da medicina (Daniels, Kennedy \& Kawachi, 2000: 94). O nosso país, por exemplo, apresenta um padrão de fortes variações em saúde, observáveis em função do sexo, da idade, do nível de escolaridade, da ocupação e da área de residência. Grupos mais envelhecidos, mais desfavorecidos, de menores rendimentos, com profissões de maior risco para a saúde, apresentam piores resultados em saúde (Santana, 2002). Na Europa Ocidental (EOc), a esperança de vida aumentou quase de forma contínua; na Europa de Leste o progresso tem sido errático. Como resultado, as disparidades na esperança média de vida para os homens são hoje maiores do que há quatro décadas. A redução da mortalidade na EOc associa-se a muitas causas de morte diferentes e revela os efeitos combinados do crescimento económico, da melhoria nos cuidados de saúde e do sucesso nas políticas de saúde (Mackenback et al., 2013). Mas a esperança média de vida parece ser maior nos países desenvolvidos mais igualitários (Wilkinson e Pickett, 2010).

Os índices de saúde e os problemas sociais tendem a ser piores nos países mais desiguais. A esperança de vida, a taxa de homicídios e de encarceramento, as gravidezes na adolescência, o grau de confiança entre as pessoas, a obesidade, as doenças mentais, entre outros indicadores, exibem uma relação robusta com os índices de desigualdade social entre países. E Portugal é dos países mais desiguais

12 O desemprego não tem que ter consequências inevitáveis ou irreversíveis sobre o estado de saúde das populações. Tal como demonstram as experiências sueca e finlandesa, o desemprego pode pôr em causa a saúde mental, mas os suicídios não têm que ser consequência inevitável. Nem devemos esperar que o sistema de saúde "junte os cacos" quando as pessoas ficam deprimidas ou suicidas. Os antidepressivos podem ajudar algumas pessoas a lidar com os efeitos do desemprego. Mas não seria melhor tratar a causa do problema e não os seus sintomas? Os suecos investiram produtivamente em programas que chegaram às pessoas que perderam empregos, ajudando-as a desenvolver um plano de regresso ao trabalho (Stuckler E Basu, 2013: 121). Os países dotados de robustos sistemas de proteção social foram capazes de manter uma tendência decrescente nas taxas de suicídio, não obstante os aumentos súbitos das taxas de desemprego (Stuckler, Basu, Suhrcke, Coutts \& Mckee, 2009) 
em todo o mundo, com um fosso crescente entre os mais ricos e os mais pobres (Wilkinson e Pickett, 2010) ${ }^{13}$. A propósito do grau de confiança entre as pessoas, perguntou-se em cada país, a amostras aleatórias da população, se concordavam ou não com a afirmação "A maior parte das pessoas são de confiança". As diferenças entre os países revelaram-se impressivas. As pessoas confiam mais umas nas outras nos países escandinavos e na Holanda; a Suécia apresenta os mais altos níveis de confiança, com $66 \%$ dos inquiridos afirmando que podem confiar nos outros. Portugal apresentou o nível mais baixo de confiança, pois apenas $10 \%$ da população mostrou acreditar que se pode confiar nos outros (Wilkinson Pickett, 2010: 80). Estes dados relacionam-se de perto com os conceitos de capital social, nomeadamente com as relações de cooperação entre os membros de bairros e comunidades, que se refletem depois nos níveis de confiança interpessoal e em normas de reciprocidade e auxílio mútuo. A qualidade das relações sociais, aferida por índices de confiança, violência e envolvimento na vida da comunidade é melhor em sociedades com menores diferenças de rendimento entre ricos e pobres (Wilkinson e Pickett, 2010). A extensa lista de factores de risco proximais, como o tabaco, os erros dietéticos e o sedentarismo, deveria também incluir a qualidade das relações sociais, na medida em que estas influenciam, de igual modo, os riscos de mortalidade (Holt-Lunstad, Smith e Layton, 2010).

\section{Adversidade}

O clima de recessão que tem vindo a afetar Portugal, ao longo dos últimos anos, motivou algumas declarações de aviso, quanto ao respetivo impacto na saúde e no bem-estar dos portugueses. Michael Marmot defendeu que as medidas de austeridade iriam causar um aumento nas taxas de desemprego e no número de suicídios (Limb, 2012). Em entrevista ao Jornal Expresso, a 22 de fevereiro de 2012, declarou que "esta crise pode custar milhares de vidas". E acrescentou que era "a pior altura possível para cortar apoios às famílias e às crianças". Do mesmo modo, a SEDES - Associação para o Desenvolvimento Económico e Social, no seu relatório de Outubro de 2013, afirmou que "a incerteza está a minar a confiança dos portugueses, com consequências para a economia e para o bem-estar da sociedade e dos cidadãos". Estas características negativas nas medidas de bem-estar não devem ser procuradas nalgum tipo de "caráter nacional", mas antes em fatores sociais, nas desigualdades e nas perceções dominantes sobre o funcionamento social (Vala, 2013). Os índices de mal-estar na comunidade, por outras palavras, devem ser compreendidos menos em termos de patologia individual e mais

13 Os dados mais recentes do European Social Survey, um inquérito presencial coordenado pelo Instituto de Ciências Sociais da Universidade de Lisboa, mostram que a promoção da igualdade e o combate à pobreza são as dimensões mais valorizadas pelos portugueses, na sua avaliação sobre o estado da democracia; mas estas dimensões são também as que recebem pior nota. Tal como refere o documento, "quanto maior a desigualdade, maior tende a ser a importância atribuída à justiça social" (Jornal Público, 18 de março de 2014). De acordo com o Instituto Nacional de Estatística, os dados mais recentes mostram um alargamento do fosso entre os $10 \%$ mais ricos e os $10 \%$ mais pobres. Com a austeridade, os rendimentos tornaram-se cada vez mais iguais nos escalões intermédios, mas ficaram mais distantes uns dos outros nas extremidades, ou seja, entre os muito ricos e os muito pobres - os $10 \%$ mais ricos ganham mais 10,7 vezes que os $10 \%$ mais pobres (jornal Público, 25 de março de 2014). 
como uma resposta coletiva à pobreza e à injustiça social que comprometem os recursos emocionais, espirituais e intelectuais essenciais ao bem-estar psicológico (Friedli, 2009).

A evidência disponível mostra que a austeridade em tempos de crise económica tem efeitos predominantemente negativos, patogénicos e iatrogénicos, sobre a saúde das pessoas e das populações (Matias Dias e Col., 2014; Bernardo, Silva e Correia, 2014). Espanha e Portugal procederam a cortes significativos nos orçamentos familiares durante os seus períodos de recessão, causando aumentos importantes no número de pessoas sem abrigo. O número dos "sem abrigo" em Barcelona aumentou $31 \%$ entre 2008 e 2011. Portugal, igualmente, teve um aumento de $25 \%$ no número dos "sem abrigo", entre 2007 e 2011 (Stuckler e Basu, 2013: 135). Ainda em Espanha, foi referido um aumento de perturbações mentais e de problemas relacionados com o álcool, no âmbito dos Cuidados Primários de Saúde, entre 2006 e 2010, sobretudo em famílias com dívidas ou afetadas pelo desemprego (Gili et al., 2012). Os efeitos da recessão constituem, portanto, uma questão de saúde pública ${ }^{14}$. Por detrás das notícias da comunicação social, sobre os detalhes da dívida e os frios números da economia, há muitas histórias por contar. Pessoas com doenças crónicas sem acesso à medicação, pessoas com doenças raras entregues aos seus cuidados, pessoas para quem a esperança numa vida melhor colapsou na vertigem suicidária (McKee et al., 2012). Talvez um dos aspetos mais sensíveis da recessão, no nosso país, se relacione com o agravamento das condições de acesso aos cuidados de saúde, motivado pela degradação das condições económicas e pela restrição do rendimento disponível (Fernandes, 2014). Neste caso, como noutros, estão em causa as consequências da austeridade e o papel dos governos, na medida em que a interação entre políticas de austeridade fiscal e choque económico, na ausência de proteção social adequada, pode estar por detrás da atual crise social, e de alguns problemas relacionados com a saúde, em vários países europeus. Mas apesar de as decisões políticas sobre o modo de responder às crises económicas terem efeitos significativos na saúde das populações, parece que os representantes institucionais, nos diferentes países, permaneceram silenciosos sobre o respetivo impacto e consequências (Karanikolos et al., 2013) ${ }^{15}$.

Os efeitos de uma recessão sobre o bem-estar e a saúde das populações não serão lineares. Nos países mais ricos, parece improvável que tenha efeitos negativos importantes sobre os indicadores globais de saúde. Contudo, a saúde dos grupos populacionais mais afetados é suscetível de sofrer

14 Stuckler e Basu (2013) proclamaram uma preocupação especial com "os argumentos ilógicos dos defensores da austeridade e com os dados objetivos sobre os seus custos humanos e económicos. Verificámos que o impacto da grande recessão foi muito para além das pessoas que perderam as suas casas e empregos. Foi um assalto em grande escala à sua saúde. No centro do argumento existe a questão sobre o que significa ser uma sociedade e qual o papel mais adequado dos governos na proteção das pessoas".

$15 \mathrm{E}$ os efeitos perniciosos da crise na saúde, alegadamente, não são inevitáveis. A Islândia rejeitou a ortodoxia associada às políticas de austeridade. Através de um referendo, cerca de $93 \%$ da população recusou um pacote de resgate proposto pelo fundo monetário internacional. Não obstante as dificuldades, a crise terá tido um efeito desprezível sobre o bem estar dos islandeses. O país investiu na proteção social e em medidas ativas de regresso ao trabalho. Os hábitos dietéticos melhoraram, na medida em que as pessoas passaram a cozinhar mais nos respetivos lares, sobretudo peixe. Foram mantidas políticas restritivas em relação ao consumo de álcool. E, finalmente, os islandeses reforçaram sentimentos de união e solidariedade num contexto económico exigente, difícil, alimentando laços de coesão e capital sociais (Karanikolos et al., 2013). 
em termos absolutos e/ou relativos, levando a um potencial alargamento das iniquidades na saúde. É também provável que aumentem doenças específicas e taxas de mortalidade por causas específicas, tais como as taxas de suicídio (Suhrcke e Stuckler, 2012). Na verdade, parece ter havido um claro aumento de suicídio depois da crise económica global de 2008. Num estudo que incluiu dados de 54 países, foi verificada a existência de um excesso de cerca de 4.900 suicídios, quando se fez a comparação com o número esperado a partir de tendências anteriores (2000-2007). Os aumentos nas taxas de suicídio nacionais em 2009, por sua vez, pareceram associar-se à magnitude dos aumentos nas taxas de desemprego, em particular para os homens e em países com baixos níveis de desemprego antes da crise (Chang et al., 2013).

Noutros períodos históricos, as crises sociais e políticas associaram-se igualmente a aumentos drásticos da morbilidade e mortalidade. Existe uma evidência consistente segundo a qual as recessões, e o desemprego em particular, podem ter consequências muito negativas na saúde mental, ao aumentarem o risco de abuso de substâncias e de suicídio, em particular nos homens mais jovens. A ausência ou debilidade dos programas de proteção social, o acesso fácil a álcool ou drogas, ou ainda a inexistência pura e simples de apoio social, real ou percebido, agravam naturalmente os efeitos deletérios das recessões no estado de saúde das sociedades (Modrek et al., 2013). Na crise económica asiática, os Malaios ignoraram o conselho da comunidade financeira internacional para reduzirem gastos na proteção social. Ao contrário do que aconteceu com os seus vizinhos, não assistiram a qualquer deterioração significativa nos padrões de saúde e bem-estar nacionais. Na antiga União Soviética, os efeitos adversos na saúde provocados pelas mudanças económicas eram substancialmente tamponados nas zonas em que as pessoas mais integravam organizações sociais, como os sindicatos ou os clubes desportivos (Stuckler, Basu, Suhrcke \& McKee, 2009). Mas na crise russa pós-comunista,

O que as estatísticas mostraram foi que muitos destes jovens morriam por intoxicação alcoólica, suicídios, homicídios e acidentes. Estas mortes pareceram fáceis de compreender: os homens cujas fábricas tinham fechado e que ficaram desempregados sofreram elevados índices de instabilidade emocional e as suas respostas passaram pelo abuso de álcool, por fazerem mal a si próprios e aos outros (Stuckler e Basu, 2013: 25)

No caso da Grande Recessão em Itália, num ambiente marcado pela subida brutal nas taxas de desemprego, tal como na Rússia no início dos anos 1990, as pessoas sentiam desesperança e viam-se também mais propensas ao comportamento suicida:

Verificámos um aumento significativo nas certidões de morte por suicídio referidas como sendo "devidas a razões económicas" durante a recessão, muito acima das tendências anteriores. Nomeadamente, as taxas de suicídio atribuíveis a todas as outras causas mantiveram-se inalteradas. Globalmente, calculámos que a Itália teve pelo menos 500 novos casos de suicídio e de tentativas de suicídio para além do que era esperado caso se mantivesse a tendência anterior à recessão (Stuckler e Basu, 2013: 110) 
A crise teve igualmente consequências na prescrição de psicofármacos. De acordo com dados recentes, Portugal apresenta uma elevada prevalência de perturbações psiquiátricas, com cerca de $23 \%$ dos portugueses a evidenciarem presença de psicopatologia nos 12 meses anteriores a uma entrevista diagnóstica (FCM, 2013). Sabendo-se que as crises económicas têm, comprovadamente, um efeito adverso na saúde mental dos grupos mais vulneráveis (WHO, 2011), é bem provável, neste contexto, que também no nosso país tenha havido um acréscimo na prescrição e consumo de psicofármacos. Mas enquanto milhões de novas prescrições eram feitas nos EUA, Inglaterra e Espanha, nem todos os países confrontados com o aumento abrupto do desemprego assistiram a aumentos tão significativos no consumo de antidepressivos. Na Suécia, as prescrições aumentaram apenas 6\% entre 2007 e 2010, muito menos do que em Espanha ou Inglaterra. Em vez de tratarem os sintomas apenas com fármacos, a resposta dos suecos durante a Grande Recessão, tal como antes, consistiu em tratar "a causa básica da depressão" - o próprio desemprego. O aumento nas taxas de suicídio não tem que ser, portanto, uma consequência inevitável do desemprego. Mais do que aumentar a prescrição de antidepressivos, os suecos investiram produtivamente em programas que ajudaram a desenvolver planos de regresso ao trabalho (Stuckler e Basu, 2013).

Robert Kennedy terá dito que o Produto Interno Bruto (PIB) dos países "mede tudo exceto aquilo que faz com que a vida valha a pena"16. Mas desde o fim da Segunda Grande Guerra, o crescimento do PIB transformou-se no objetivo central da política económica para muitos países (Costanza et al., 2014). Ora, esta orientação tem criado instabilidade social. Há mais de 200 anos, John Stuart Mill defendeu que os esforços das sociedades deveriam alimentar o lazer e o progresso social e moral, e não a competição pelos bens materiais, uma vez assegurados padrões de vida decentes. É neste contexto que é hoje valorizada uma atenção particular ao bem-estar das pessoas, nas diferentes sociedades, incluindo elementos de avaliação objetivos e subjetivos. O sucessor do PIB deveria ser uma métrica que integrasse conhecimentos sobre o modo como a ecologia, a economia, a psicologia e a sociologia podem contribuir, em conjunto, para medir e construir um bem-estar sustentável para as populações (Costanza et al., 2014). Deveria haver uma mudança que privilegiasse o bem estar das pessoas e não apenas os estritos critérios de desenvolvimento económico, atenta às condições objetivas e às capacidades das pessoas para terem uma qualidade de vida digna, num clima de justiça social (Stiglitz, Sen e Fitoussi, 2009). O progresso da humanidade não deve ser sinónimo de progresso na economia. Se acreditarmos, como Robert Kennedy, que o progresso resulta de um desenvolvimento saudável para as nossas crianças, da beleza da nossa poesia, da estabilidade e segurança nas nossas famílias, ou do exercício da inteligência no debate público, então devemos encontrar medidas de progresso mais adequadas ao justo respeito pela saúde, pela liberdade e dignidade dos nossos concidadãos (Dietz e O'Neill, 2013). Afinal,

16 o produto nacional bruto não garante a saúde das nossas crianças, a qualidade da sua educação ou a alegria das suas brincadeiras. Não inclui a beleza da nossa poesia ou a solidez dos nossos casamentos, a inteligência do nosso debate público ou a integridade dos nossos funcionários públicos. Não mede a nossa perspicácia nem a nossa coragem, a nossa sabedoria ou a nossa aprendizagem, a nossa compaixão ou a devoção ao nosso país. Mede tudo, afinal, excepto aquilo que faz com que a vida valha a pena (Robert F. Kennedy, 1968, in Dietz e O'Neill, 2013) 
Quando falarmos aos nossos filhos sobre a Grande Recessão, eles julgar-nos-ão não pelas taxas de crescimento ou pela redução do défice. Julgar-nos-ão pela forma como cuidámos dos mais vulneráveis e se optámos por dar atenção às necessidades de saúde mais básicas das nossas comunidades: cuidados de saúde, alojamento, emprego... A riqueza fundamental de qualquer sociedade está no seu povo. Investir na sua saúde é uma escolha sensata quando as coisas correm bem e uma necessidade urgente quando as coisas correm mal (Stuckler e Basu, 2013: 145).

\section{Bibliografia}

Bernardo, L., Silva, M., Correia, T. (2014). A saúde pública como investimento social. In Carmo, R. M. e Barata, A. (Org.), Estado Social. De todos para Todos (pp. 91-134). Lisboa. Tinta da China.

Braveman, P., \& Gottlieb, L. (2014). The Social Determinants of Health: It's Time to Consider the Causes of the Causes. Public HEALTH REPORTS.

Bruner, J. S. (1990). Acts of meaning. Cambridge. Harvard University Press.

CAREY, N.. (2012). THE EPIGENETICS REVOLUTION: HOW MODERN BIOLOGY IS REWRITING OUR UNDERSTANDING OF GeNETICS, DISEASE, AND INHERITANCE. LONDON. ICON.

Champagne, F. A. (2010). Early Adversity and Developmental Outcomes Interaction Between Genetics, Epigenetics, and Social EXperiences Across the Life Span. Perspetives on Psychological SCience (5) 564-574

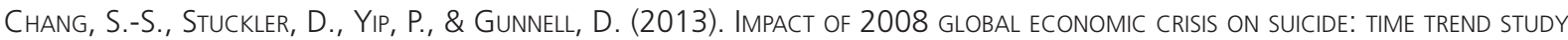
IN 54 COUNTRIES. BMJ (CLINICAL RESEARCH ED.), 347, F5239.

Choudhury, S., Nagel, S. K., \& Slaby, J. (2009). Critical neuroscience: Linking neuroscience and society through Critical PRACTICE. BIOSOCIETIES, 4, 61-77

Costanza, R., Kubiszewski, I., Giovannini, E., Lovins, H., McGlade, J., Pickett, K. E., et al. (2014). Development: Time to leave GDP BEHIND. NATURE, 505(7483), 283-285.

Cranor, C. F. (2013). Assessing genes as causes of human disease in a multicultural world. In Krimsky, S, Gruber, J. (Eds.), Genetic explanations: Sense and Nonsense (pp. 107-121). Cambridge, Harvard University Press.

Daniels, N., Kennedy, B. \& Kawachi, I. (2000). Is inequality bad for our health? Beacon Press.

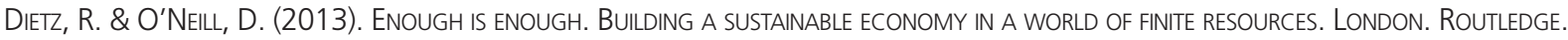
Evangelli Gaudium (2013). Lisboa. Paulus Editora.

Farinha Rodrigues (2013). Pobreza. In Cardoso, J. L., Magalhães, P., Machado Pals, J. (Org). Portugal de A a Z (pp 191-203). Paço de Arcos. IMPResa Publishing/EXPRESSO

FCM (2013). Estudo epidemiológico nacional de saúde mental - $1^{\circ}$ Relatório. Lisboa. Faculdade de CiênCias Médicas da UNIVERSIDADE NOVA DE LISBOA.

Fernandes, A., C. (2014). Crise, austeridade e saúde. In Paz Ferreira, E. (Coord), A austeridade cura? A austeridade mata? (927-953). LISBOA. LISBON LAW SCHOOL EDITION.

Friedl, L. (2009). Mental health, Resillence And Inequalities. WHO, Europe.

GARCY, A. M., \& VÅGERÖ, D. (2012). THE LENGTH OF UNEMPLOYMENT PREDICTS MORTALITY, DIFFERENTLY IN MEN AND WOMEN, AND BY CAUSE

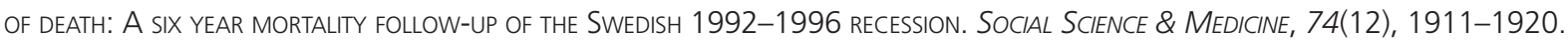

GARCY, A. M., \& VÅGERÖ, D. (2013). UNEMPLOYMENT AND SUICIDE DURING AND AFTER A DEEP RECESSION: A LONGITUDINAL STUDY OF 3.4 million SWedish men and WOMen. American Journal of Public Health, 103(6), 1031-1038.

Gili, M., Roca, M., Basu, S., McKee, M., \& Stuckler, D. (2013). The mental health Risks of eConomic crisis in Spain: evidence fRom PRIMARY CARE Centres, 2006 and 2010. EuRopean Journal of Public HEALth, 23(1), 103-108. 
Goldhaber, D. (2012). Nature-nurture debates. Bridging the gap. Cambridge University Press.

Gould, S. J. (1988). O Mundo depois de DarWin. Editorial Presença. Lisboa.

Gruber, J. (2013). Conclusion: The unfulfilled promise of genomics. In Krimsky, S, Gruber, J. (Eds.), Genetic eXplanations: Sense and Nonsense (pp. 270-282). Cambridge, HarVard University Press.

Hertzman, C., \& Boyce, T. (2010). How experience gets under the skin to CReate gradients in Developmental health. Annual ReView of Public Health, 31, 329-47.

Ho, Mae-Wan (2013). Nuturing nature: How parental care Changes genes. In Krimsky, S, Gruber, J. (Eds.), Genetic explanations: Sense And Nonsense (pp. 256-269). Cambridge, HarVard University Press.

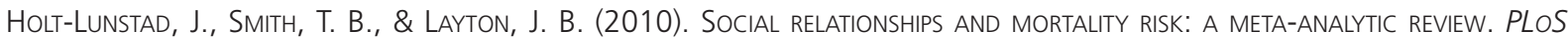
MEDICINE, 7(7)

INE, PoRTugal (2013). INCOME AND LIVING CONDITIONS.

Jablonka, E. (2013). Some problems With Genetic horoscopes. In KRimsky, S, Gruber, J. (Eds.), Genetic explanations: Sense and Nonsense (pp. 71-80). CAMBridge, Harvard University Press.

Karanikolos, M., Mladovsky, P., Cylus, J., Thomson, S., Basu, S., Stuckler, D., et al. (2013). Financial Crisis, austerity, and HEALTH IN EUROPE. LANCET, 381(9874), 1323-1331.

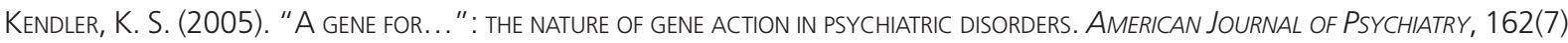

Kirmayer, L. J., \& Gold, I. (2012). Re-Socializing Psychiatry. In CRitical Neuroscience: a Handbook of the Social and Cultural CONTEXT OF NEUROSCIENCE (PP. 307-330)

Kirmayer, L. J. (2012). The future of Critical neuroscience. In CRitical Neuroscience: a Handbook of the Social and Cultural CONTEXT OF NEUROSCIENCE (PP. 367-383)

KLeinman, A., \& Benson, P. (2006). Anthropology in the Clinic: the PROBlem of CULtURAL COMPETENCY AND hOW to FiX it. PLoS MEDICINE, 3(10), E294.

Krieger, N. (2011). Epidemiology and the people's health: Theory and context. Oxford University Press.

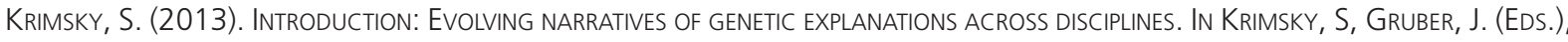
Genetic explanations: Sense and Nonsense (pp. 1-13). Cambridge, Harvard University Press.

Landecker, H., \& Panofsky, A. (2013). From Social Structure to Gene Regulation, and Back: A Critical introduction to EnVironmental Epigenetics for Sociology. Annual ReView of Sociology, Vol. 39: 333-357

LeVins, R., Lewontin, R. (1985). The Dialectical Biologist. Cambridge. Harvard University Press.

LeWontin, R. C. (2001). The triple heliX: Gene, ORganism, AND ENVIRONMENT. HARVARD UniverSity PresS.

LIMB, M. (2012). AusteriTY MEASURES WILl LEAD tO RISE IN UNEMPLOYMENT AND SUICIDES, SAYS MARMOt. (BMJ;344:E2887)

Link, B. G., \& Phelan, J. (1995). Social conditions as fundamental causes of disease. Journal of Health and Social BehaVior, SPEC No, 80-94.

Lock, M. (2013). The epigenome and nature/Nurture reunification: a Challenge for anthropology. Medical Anthropology, 32(4), 291-308.

Mackenbach, J. P., Karanikolos, M., \& McKee, M. (2013). The unequal health of Europeans: successes and failures of policies. LANCET, 381(9872), 1125-1134.

Matias Dias, C., Fonseca, R., Contreiras, T., \& Pereira Miguel, J. (2014). Os efeitos da austeridade na saúde da população: EVidência internacional e experiênCia portuguesa. In Paz Ferreira, E. (Coord), A austeridade cura? A austeridade mata? (927-953). LISBOA. LISBON LAW SCHOOL EDITIONS.

McEWen, B. S. (2012). Brain on StRess: hoW the social enVIRonment Gets under the skin. ProceEdings of the National Academy of SCIENCES OF THE UNITED StATES OF AMERICA, 109 SUPPL 2, 17180-17185.

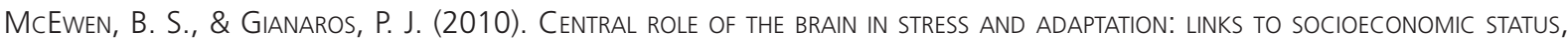
health, and disease. Annals of the NeW York ACADEMy of SCIENCES, 1186, 190-222. 
McGoWAN, P. O., \& SZYF, M. (2010). THE EPIGENETICS OF SOCIAL ADVERSITY IN EARLY LIFE: IMPLICATIONS FOR MENTAL HEALTH OUTCOMES. NEUROBIOLOGY OF DISEASE, 39(1), 66-72.

McKee, M., Karanikolos, M., Belcher, P., \& Stuckler, D. (2012). Austerity: a falled experiment on the people of Europe. Clinical MEDICINE (LONDON, ENGLAND), 12(4), 346-350.

Meaney, M. J. (2001). Nature, nurture, and the disunity of knowledge. Annals of the New York Academy of Sciences, $935,50-61$.

Meaney, M. J. (2010). Epigenetics and the biological definition of Gene X enVIRONMEnt interactions. Child DeVelopment, $81(1), 41-79$

Miller, G. (2010, July 2). Epigenetics. The seductive allure of behavioral epigenetics. SCience, pp. 24-27.

Modrek, S., Stuckler, D., \& McKee, M. (2013). A Review of Health Consequences of Recessions Internationally and a Synthesis of the US Response during the Great Recession. Public Health Reviews.

National Scientific Council on the Developing Child (2010). Early Experiences Can Alter Gene Expression and Affect Long-Term DeVElopment: Working Paper No. 10. RetrieVed from WWW.deVelopingChILD. HARVARD.edu

Quartillo, M. J. (1988). A Propósito da SOCIOBIologia. Psiquiatria Clínica, 9 (3)

Raphael, D. (2009). Social determinants of health: Canadian perspetives. Canadian Scholars Press.

Rose, H., \& Rose, S. (2012). Genes, cells and brains: The promethean Promises of the new biology. London. Verso.

Rose, N. S., \& Abi-Rached, J. M. (2013). Neuro: The new brain sciences and the management of the mind. Princeton UNIVERSITY PRESS.

Rose, S. (2005). LIFELINES: LIFE BEYOND THE GENE. London. VINTAGE.

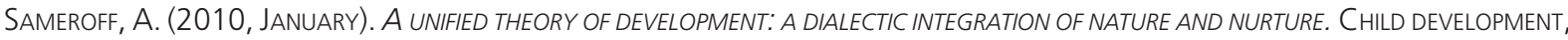
$81,1,6-22$

Santana, P. (2002). Poverty, social exclusion and health in Portugal. Social Science \& Medicine (1982), 55(1), 33-45.

Shonkoff, J. P., Boyce, W. T., \& McEwen, B. S. (2009). Neuroscience, molecular biology, and the ChildhoOd ROOTS of health DISPARITIES: BUILDING A NEW FRAMEWORK FOR HEALTH PROMOTION AND DISEASE PREVENTION. JAMA : THE JOURNAL OF tHE AMERICAN MEDICAL ASSOCIATION, 301(21), 2252-2259.

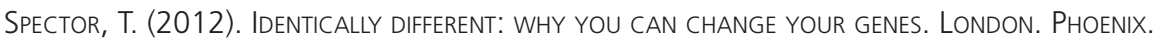

Stiglitz, J., Sen, A., \& Fitoussi, J. P. (2009). Report by the Commission on the MEASUREMENT of ECONOMic PeRformance AND SOCIAL PROGRESS, WWW.STIGLITZ-SEN-FITOUSSI.FR/DOCUMENTS/RAPPORT_ANGLAIS.PDF

Stuckler, D., \& Basu, S. (2013). The body eConomic: Why austerity killis. London. Allen Lane.

Stuckler, D., Basu, S., Suhrcke, M., \& McKee, M. (2009A). The health implications of financial CRisis: a review of the evidence. THE UlSter Medical JOURnal, 78(3), 142-145.

Stuckler, D., Basu, S., Suhrcke, M., Coutts, A., \& McKee, M. (2009). The public health effect of economic crises and ALTERNATIVE POLICY RESPONSES IN EUROPE: AN EMPIRICAL ANALYSIS. THE LANCET, 374:315-23

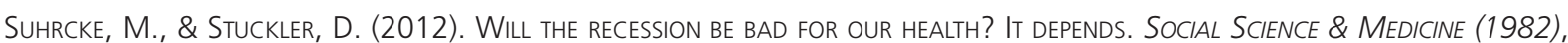
74(5), 647-653.

Tallis, R. (2011). Aping Mankind: Neuromania, Darwinitis And The Misrepresentation Of Humanity. Acumen Pub,

Vala, J. (2013). Bem-estar. In Cardoso, J. L., Magalhães, P., Machado Pais, J. (Org). Portugal de A a Z (pp 21-31). Paço de ARCOS. IMPRESA PUBLISHING/EXPRESSO

Venkatapuram, S. (2011). Health justice: An argument from the capabilities approach. Cambridge. Polity.

Who (2001). The world health report. Mental Health: New Understanding, New Hope. Geneva.

WHO (2011). Impact of EConomic crisis on mental health. Copenhagen. WHO Regional Office for Europe. 
WHO (2013). KEY CONCEPTS IN SOCIAL DETERMINANTS OF HEALTH (DISPONIVEL EM HTTP://WWW.WHO.INT/SOCIAL_DETERMINANTS/ THECOMMISSION/FINALREPORT/KEY_CONCEPTS/EN/INDEX.HTML)

Wilkinson, R. G., \& Marmot, M. G., Eds. (2003). Social determinants of health: the SOlid facts. $2^{\text {No }}$ edition.

Wilkinson, R, Pickett, K. (2010). The spirit level. Why more equal societies almost always do better. London. Allen Lane.

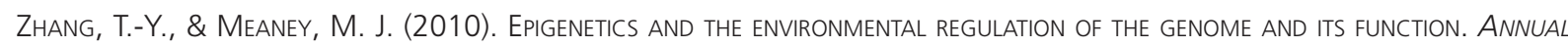
REVIEW OF PSYCHOLOGY, 61, 439-66 